\title{
RESEARCH
}

Open Access

\section{Maldistribution of pulmonary blood flow in patients after the Fontan operation is associated with worse exercise capacity}

Tarek Alsaied ${ }^{1}$, Lynn A. Sleeper ${ }^{1,2}$, Marco Masci', Sunil J. Ghelani ${ }^{1,2}$, Nina Azcue ${ }^{1}$, Tal Geva ${ }^{1,2}$, Andrew J. Powell ${ }^{1,2}$ and Rahul H. Rathod ${ }^{1,2^{*}}$

\begin{abstract}
Background: Maldistribution of pulmonary artery blood flow (MPBF) is a potential complication in patients who have undergone single ventricle palliation culminating in the Fontan procedure. Cardiovascular magnetic resonance (CMR) is the best modality that can evaluate MPBF in this population. The purpose of this study is to identify the prevalence and associations of MPBF and to determine the impact of MPBF on exercise capacity after the Fontan operation.

Methods: This retrospective single-center study included all patients after Fontan operation who had maximal cardiopulmonary exercise test (CPET) and CMR with flow measurements of the branch pulmonary arteries. MPBF was defined as $>20 \%$ difference in branch pulmonary artery flow. Exercise capacity was measured as percent of predicted oxygen consumption at peak exercise (\% predicted $\left.\mathrm{VO}_{2}\right)$. Linear and logistic regression models were used to determine univariate and multivariable predictors of exercise capacity and correlates of MPBF, respectively.

Results: A total of 147 patients who had CMR between 1999 and 2017 were included (median age at CMR 21.8 years [interquartile range (IQR) 16.5-30.6]) and the median time between CMR and CPET was 2.8 months [IQR 0-13.8]. Fiftythree patients (36\%) had MPBF (95\% Cl 29-45\%). The mean \% predicted $\mathrm{VO}_{2}$ was $63 \pm 16 \%$. Patients with MPBF had lower mean $\%$ predicted $\mathrm{VO}_{2}$ compared to patients without MPBF ( $60 \pm 14 \%$ versus $\left.65 \pm 16 \%, p=0.04\right)$. On multivariable analysis, a lower \% predicted $\mathrm{VO}_{2}$ was independently associated with longer time since Fontan, higher ventricular mass-to-volume ratio, and MPBF. On multivariable analysis, only compression of the branch pulmonary arteries by the ascending aorta or aortic root was associated with MPBF (OR 6.5, 95\% Cl 5.6-7.4, $p<0.001)$.

Conclusion: In patients after the Fontan operation, MPBF is common and is independently associated with lower exercise capacity. MPBF was most likely to be caused by pulmonary artery compression by the aortic root or the ascending aorta. This study identifies MPBF as an important risk factor and as a potential target for therapeutic interventions in this fragile patient population.
\end{abstract}

Keywords: Fontan procedure, Maldistribution of pulmonary blood flow, Cardiovascular magnetic resonance imaging, Congenital heart disease, Exercise capacity

\footnotetext{
* Correspondence: rahul.rathod@cardio.chboston.org

'Department of Cardiology, Boston Children's Hospital, Boston, MA, USA

2Department of Pediatrics, Harvard Medical School, Boston, MA, USA
}

(c) The Author(s). 2018 Open Access This article is distributed under the terms of the Creative Commons Attribution 4.0 International License (http://creativecommons.org/licenses/by/4.0/), which permits unrestricted use, distribution, and reproduction in any medium, provided you give appropriate credit to the original author(s) and the source, provide a link to the Creative Commons license, and indicate if changes were made. The Creative Commons Public Domain Dedication waiver (http://creativecommons.org/publicdomain/zero/1.0/) applies to the data made available in this article, unless otherwise stated. 


\section{Background}

Despite the significant improvement in outcomes after the Fontan operation, complications and comorbidities are still common $[1,2]$. Optimizing the Fontan circuit is an important factor in reducing these comorbidities [3]. Cardiovascular magnetic resonance (CMR) has been shown to be a valuable tool to predict adverse outcomes in Fontan patients. One of the quantitative measurements by CMR is blood flow to each branch pulmonary artery $[4,5]$. Studies evaluating Fontan patients have suggested that up to $45 \%$ of patients have maldistribution of pulmonary blood flow (MPBF), defined as a difference between left pulmonary artery (LPA) and right pulmonary artery (RPA) blood flow of $>20 \%$ [4].

The etiology of MPBF in the Fontan circulation is likely multifactorial due to different anatomic and physiologic abnormalities [6]. Some studies suggest that the LPA can become compressed by the aortic root or ascending aorta, especially in patients with hypoplastic left heart syndrome (HLHS) [7]. RPA twisting may be associated with the extracardiac Fontan modification [8]. Lung pathologies including pulmonary hypoplasia and pulmonary vascular disease are common in Fontan physiology and may also result in MPBF [6]. Furthermore, compression of pulmonary venous return may occur due to atrial dilation or by the Fontan conduit or baffle $[9,10]$. These subtle abnormalities can lead to MPBF which may result in adverse hemodynamics. The associations of MPBF with exercise capacity and other clinical outcomes are largely unknown $[11,12]$. The purpose of this study is to identify the impact of MPBF on exercise capacity and clinical outcomes in patients after the Fontan operation.

\section{Methods}

\section{Patients}

A database search identified all post-operative Fontan patients who had a CMR study and cardiopulmonary exercise test (CPET) at Boston Children's Hospital between January 1999 and July 2017. Patients were included if differential branch pulmonary artery (PA) flow could be calculated by CMR and if they had a maximal effort on exercise stress testing, defined as a respiratory exchange ratio of $\geq 1.09$ or a heart rate of $\geq 75 \%$ predicted. Patients were excluded if there were any interventions or procedures between the CMR and CPET or if the period between CPET and CMR was more than 2 years. The Boston Children's Hospital Committee on Clinical Investigation approved this retrospective study and waived the requirement for informed consent.

\section{CMR}

CMR studies were performed with 1.5 Tesla scanners (Philips Healthcare, Best, the Netherlands or GE Medical Systems, Milwaukee, Wisconsin). The details of the CMR protocols used in our laboratory for assessment of patients after the Fontan operation have been published [13-15]. Briefly, ventricular assessment was performed by an electrocardiographically-gated, balanced steady-state free precession (bSSFP) cine CMR in vertical and horizontal ventricular long-axis planes, and a stack of slices in a ventricular short-axis plane encompassing the atrioventricular junction through the cardiac apex. Retrospectively cardiac gated, free-breathing, through-plane phase-contrast flow meaurements were obtained in the branch pulmonary arteries and vena cavae. Care was taken to align the imaging plane perpendicular to flow and to obtain slice positions and orientations that were proximal to the PA branching [4].

\section{CMR data analysis}

If a patient had multiple CMR studies, the most recent study with complete flow data was used for analysis. MPBF was calculated by direct measurement of the branch PA flow on phase contrast imaging. Branch PA flow was measured by manually tracing each branch PA on phase contrast imaging using QFlow (Medis Medical Imaging Systems, Leiden, The Netherlands) (Fig. 1a) [16]. Percentage flow to each PA was calculated. In patients without baffle leaks or patent fenestrations who had unilateral PA stents where direct PA flow could not be measured, flow in the stented PA was calculated using the following formula: superior vena cava flow+ inferior vena cava flow - the non-stented branch PA flow. Branch PA cross-sectional area was calculated by measuring two orthogonal dimensions at the narrowest segment and indexed to body surface area (Fig. 1b). A branch PA symmetry index (PASI) was calculated as the ratio of the area of the smaller pulmonary artery to the larger pulmonary artery. PASI is always $\leq 1$ with values closer to 1 reflecting more symmetric branch PAs [17]. PA compression by the ascending aorta or aortic root was determined by review of CMR images by a provider who was blinded to the PA blood flow distribution. PA compression was defined as narrowing of the branch PA to $<75 \%$ of its original diameter as it crossed posterior to the ascending aorta or the aortic root (Fig. 1c) [18]. Lung volumes were calculated by Simpson's method using manual tracing of the lung fields in each slice on an axial image bSSFP stack (Fig. 1d). Lung volume discrepancy was defined as the absolute value of the difference between the right and left lung volume percentage. Aortic root total area was measured by adding dominant to non-dominant aortic root area as measured on axial planes [19].

Ventricular volumes and function were measured by manual tracing of endocardial and epicardial borders on each short-axis bSSFP cine slice at end-diastole (maximal volume) and end-systole (minimal volume) as 

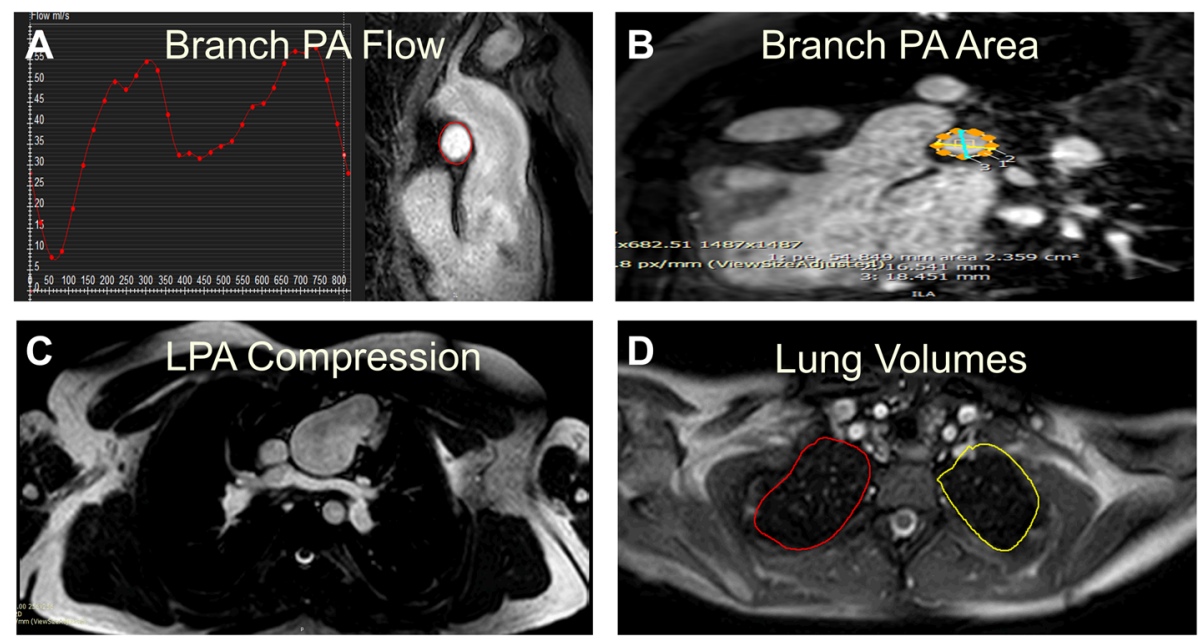

Fig. 1 Cardiovascular magnetic resonance (CMR) example of different measurements used in our study. a Branch pulmonary artery (PA) flow measurement. b Branch PA cross-sectional area was calculated by measuring two orthogonal dimensions at the narrowest segment. $\mathbf{c}$ Left pulmonary artery (LPA) compression by a dilated ascending aorta. $\mathbf{d}$ Lung volume calculation by Simpson's method using manual tracing in each slice on an axial image balanced steady-state free precession stack

previously described $[5,15]$. Analysis was performed using commercially available software (QMass, Medis Medical Imaging Systems, Leiden, The Netherlands) and $\left(\mathrm{cmr}^{42}\right.$, Circle Cardiovascular Imaging Inc., Calgary, Canada).

\section{Clinical parameters}

Demographic and clinical data, including underlying diagnoses and type of single ventricle based on ventricular dominance, were abstracted from the medical records. The type of surgical palliation was classified as lateral tunnel, extracardiac conduit, right atrium-to-PA anastomosis, or right atrium-to-right ventricle connection. Additional parameters included age at Fontan, time from Fontan to CMR, and number and type of surgical and catheterization interventions before and after CMR. Arrhythmia history was compiled by review of Holter monitors, electrocardiograms, electrophysiology catheterizations, and clinic notes. Other relevant clinical variables included a history of heart failure (defined as New York Heart Association class II or greater), protein-losing enteropathy, stroke, thrombus, seizures, liver disease, or pacemaker or defibrillator placement.

\section{Cardiopulmonary exercise testing}

A maximal CPET was performed using a calibrated cycle ergometer and ramp protocol (Corival Load Cycle 400, Lode BV, Groningen, The Netherlands). The test starts with setting an initial work rate based on the patient's body surface area (BSA) with linear increases every minute reaching a peak exercise after $10 \mathrm{~min}$. Gas exchange was analyzed at rest, during exercise, and during recovery to determine measures of oxygen uptake $\left(\mathrm{VO}_{2}\right)$ [20]. Since peak $\mathrm{VO}_{2}$ is influenced by age, sex, and body weight, the percent of predicted peak $\mathrm{VO}_{2}$ value (\% predicted $\mathrm{VO}_{2}$ ) was used due to the wide age range in this study [21].

\section{Statistical analysis}

The Student t-test or Mann-Whitney U test was used to compare two groups of continuous symmetric or non-symmetric variables, respectively, or Fisher exact for categorical variables, as appropriate. A normal approximation to binomial confidence interval was constructed for the percentage of patients with MPBF. Univariate association between normally distributed variables was estimated using the Pearson correlation coefficient. A stepwise multivariable linear regression modeling procedure with 0.1 as the significance level for entry and 0.05 as the significance level for retention in the model was constructed to determine independent predictors of $\%$ predicted $\mathrm{VO}_{2}$. A stepwise multivariable logistic regression model with 0.1 as the significance level for entry and 0.05 as the significance level for retention in the model was constructed to identify the independent factors associated with the presence or absence of MPBF. Continuous predictor variables were also categorized into tertiles to assess potential nonlinearity, but no nonlinear significant associations were found (data not shown). All $p$-values were two-tailed (where applicable) and differences and associations were considered significant when $p<0.05$. Statistical analyses were performed using SPSS Statistics for Windows, Version 24.0 (International Business Machines, Armonk, New York, USA) and $\mathrm{JMP}^{\circ}$, Version 12 (SAS Institute Inc., Cary, North Carolina, USA). 


\section{Results}

There were 147 patients who met inclusion criteria with complete CMR PA blood flow data and CPET without interval intervention. Most patients had direct PA blood flow assessment in both PAs; there were 3 patients who had a PA stent requiring calculation using venae cavae flow measurements. The median age at CMR was 21.8 years [interquartile range (IQR) 16.5-30.6]. The median time between CMR and CPET was 2.8 months [IQR 013.8]. There was no significant difference in the time from

Table 1 Patient Demographic and Clinical Characteristics

\begin{tabular}{|c|c|c|c|c|}
\hline & All Patients $(n=147)$ & Patients with MPBF $(n=53)$ & Patients without MPBF $(n=94)$ & $P$ Value \\
\hline Age at Fontan (yr)+ & $3.2[2.2-6]$ & $2.9[2-4.8]$ & $3.3[2.3-7.6]$ & 0.21 \\
\hline Age at CMR (yr) & $21.8[16.5-30.6]$ & $20.7[16.5-25]$ & $23.2[16.6-32.2]$ & 0.20 \\
\hline Time since Fontan (yr) & $17.2[13.1-22.9]$ & 16.5 [13.1-20.9] & $17.9[12.9-23.9]$ & 0.23 \\
\hline Time between CMR and CPET (mos) & $2.8[0-13.8]$ & $1[0-14.5]$ & $4.5[0-11.5]$ & 0.10 \\
\hline Body surface area at CMR $\left(\mathrm{m}^{2}\right)$ & $1.7[1.5-1.9]$ & $1.7[1.5-1.8]$ & $1.7[1.5-2]$ & 0.52 \\
\hline Cardiac Diagnosis & & & & 0.14 \\
\hline Tricuspid atresia & $37(25 \%)$ & $14(26 \%)$ & $23(24 \%)$ & \\
\hline Double-inlet left ventricle & $24(16 \%)$ & $7(13 \%)$ & $17(18 \%)$ & \\
\hline HLHS & $25(17 \%)$ & $14(26 \%)$ & $11(12 \%)$ & \\
\hline Unbalanced AV canal & $9(6 \%)$ & $4(8 \%)$ & $5(5 \%)$ & \\
\hline Double-outlet right ventricle & $25(17)$ & $9(17 \%)$ & $16(17 \%)$ & \\
\hline Complex 2 ventricle & $13(9 \%)$ & $2(4 \%)$ & $11(12 \%)$ & \\
\hline Hypoplastic TV/RV & $6(4 \%)$ & $0(0 \%)$ & $6(7 \%)$ & \\
\hline Pulmonary atresia/IVS & $2(1 \%)$ & $1(2 \%)$ & $1(1 \%)$ & \\
\hline Mitral atresia & $6(4 \%)$ & $2(4 \%)$ & $4(4 \%)$ & \\
\hline Levocardia & $122(83 \%)$ & $78(83 \%)$ & $44(83 \%)$ & 0.90 \\
\hline HLHS only & $25(17 \%)$ & $14(26 \%)$ & $11(12 \%)$ & 0.04 \\
\hline Heterotaxy & $17(12 \%)$ & $8(16 \%)$ & $9(10 \%)$ & 0.23 \\
\hline Genetic diagnosis & $11(7 \%)$ & $5(9 \%)$ & $6(6 \%)$ & 0.45 \\
\hline Dominant ventricular morphology & & & & 0.68 \\
\hline Left ventricle & $58(40 \%)$ & $19(42 \%)$ & $39(42 \%)$ & \\
\hline Right ventricle & 49 (33\%) & $20(32 \%)$ & $29(31 \%)$ & \\
\hline 2 ventricles & $40(27 \%)$ & $14(26 \%)$ & $26(27 \%)$ & \\
\hline History of neonatal surgery & 79 (54\%) & $34(64 \%)$ & $45(48 \%)$ & 0.06 \\
\hline History of Glenn operation & 75 (51\%) & $33(62 \%)$ & $39(41 \%)$ & 0.02 \\
\hline History of Damus-Kaye-Stansel & $42(29 \%)$ & $21(40 \%)$ & $21(22 \%)$ & 0.04 \\
\hline Bilateral Glenn operation & $13(8.8 \%)$ & $5(10 \%)$ & $8(10 \%)$ & 0.50 \\
\hline Fontan Type & & & & 0.43 \\
\hline Lateral tunnel & $98(67 \%)$ & $41(77 \%)$ & $57(60 \%)$ & \\
\hline RA-Pulmonary artery & $31(21 \%)$ & $8(15 \%)$ & $23(25 \%)$ & \\
\hline Extracardiac & $11(8 \%)$ & $3(6 \%)$ & $8(11 \%)$ & \\
\hline RA-RV Fontan & $5(3.4 \%)$ & $1(2 \%)$ & $4(4 \%)$ & \\
\hline History of any PA intervention ${ }^{a}$ & $34(23 \%)$ & $20(38 \%)$ & $13(14 \%)$ & 0.004 \\
\hline History of PA intervention before Fontan & $12(8 \%)$ & $10(19 \%)$ & $2(2 \%)$ & 0.001 \\
\hline History of PA intervention at Fontan & $3(2 \%)$ & $1(2 \%)$ & $2(2 \%)$ & 0.70 \\
\hline History of PA intervention after Fontan & $19(13 \%)$ & $10(19 \%)$ & $9(10 \%)$ & 0.09 \\
\hline Pulmonary vein stenosis ${ }^{a}$ & $5(3 \%)$ & $4(7 \%)$ & $1(1 \%)$ & 0.06 \\
\hline
\end{tabular}

Abbreviations: $A V$ atrioventricular, CMR cardiovascular magnetic resonance, CPET cardiopulmonary exercise test, HLHS hypoplastic left heart syndrome, IVS intact ventricular septum, MPBF maldistribution of pulmonary blood flow, $P A$ pulmonary artery, $R A$ right atrium, $R V$ right ventricle, $T V$ tricuspid valve

${ }^{\text {a }}$ Prior to CMR. + Data presented as median [interquartile range] 


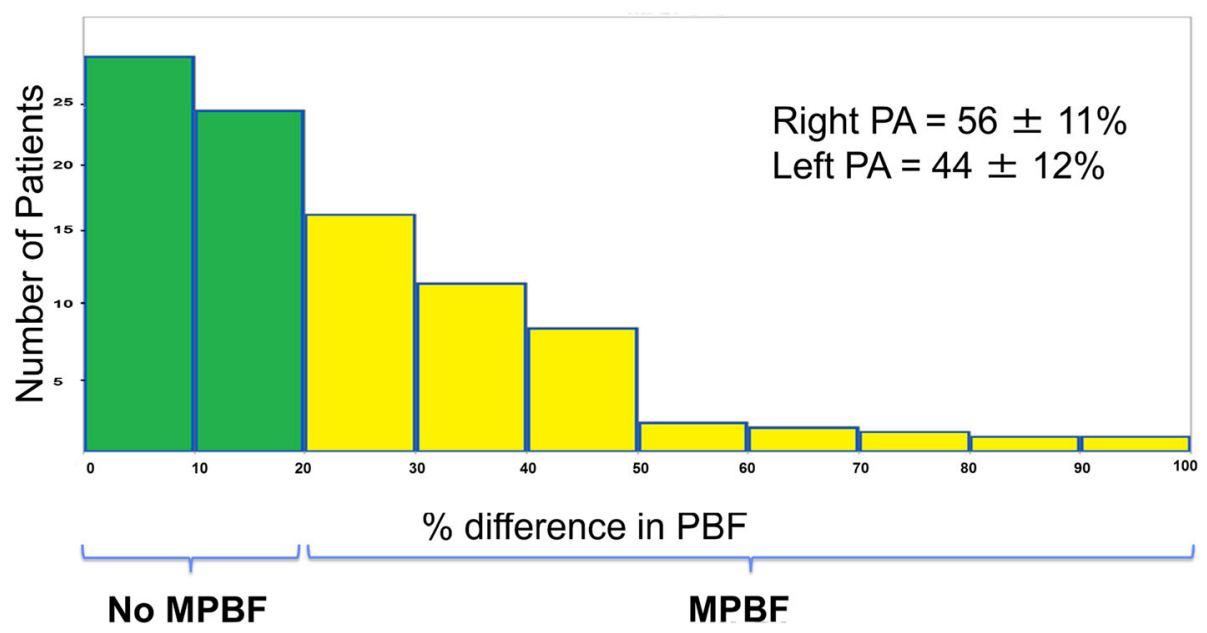

Fig. 2 Percentage difference in branch PA blood flow between the two branch PAs. The mean branch PA flow is 56\% to the right PA. Green denotes no MPBF (\%difference < 20); yellow denotes MPBF (\%difference $\geq 20$ ). MPBF: Maldistribution of pulmonary blood flow. PA: Pulmonary artery. PBF: Pulmonary blood flow

CMR to CPET between patients with and without MPBF. Patient characteristics are summarized in Table 1 [4].

\section{Distribution of pulmonary blood flow}

MPBF was present in 53 patients (36\%, 95\% CI 2945\%). A histogram of differential PA blood flow is shown in Fig. 2. Total PA blood flow was $2.46 \pm 0.6 \mathrm{~L} /$ $\mathrm{m}^{2}$. Average LPA blood flow was $1.07 \pm 0.35 \mathrm{~L} / \mathrm{m}^{2}$ which represented $44 \pm 12 \%$ of total PA flow. Average RPA blood flow was $1.38 \pm 0.44 \mathrm{~L} / \mathrm{m}^{2}$ which represented $56 \pm 11 \%$ of total PA flow. There was a weak correlation between branch PA flow percentage and ipsilateral PA
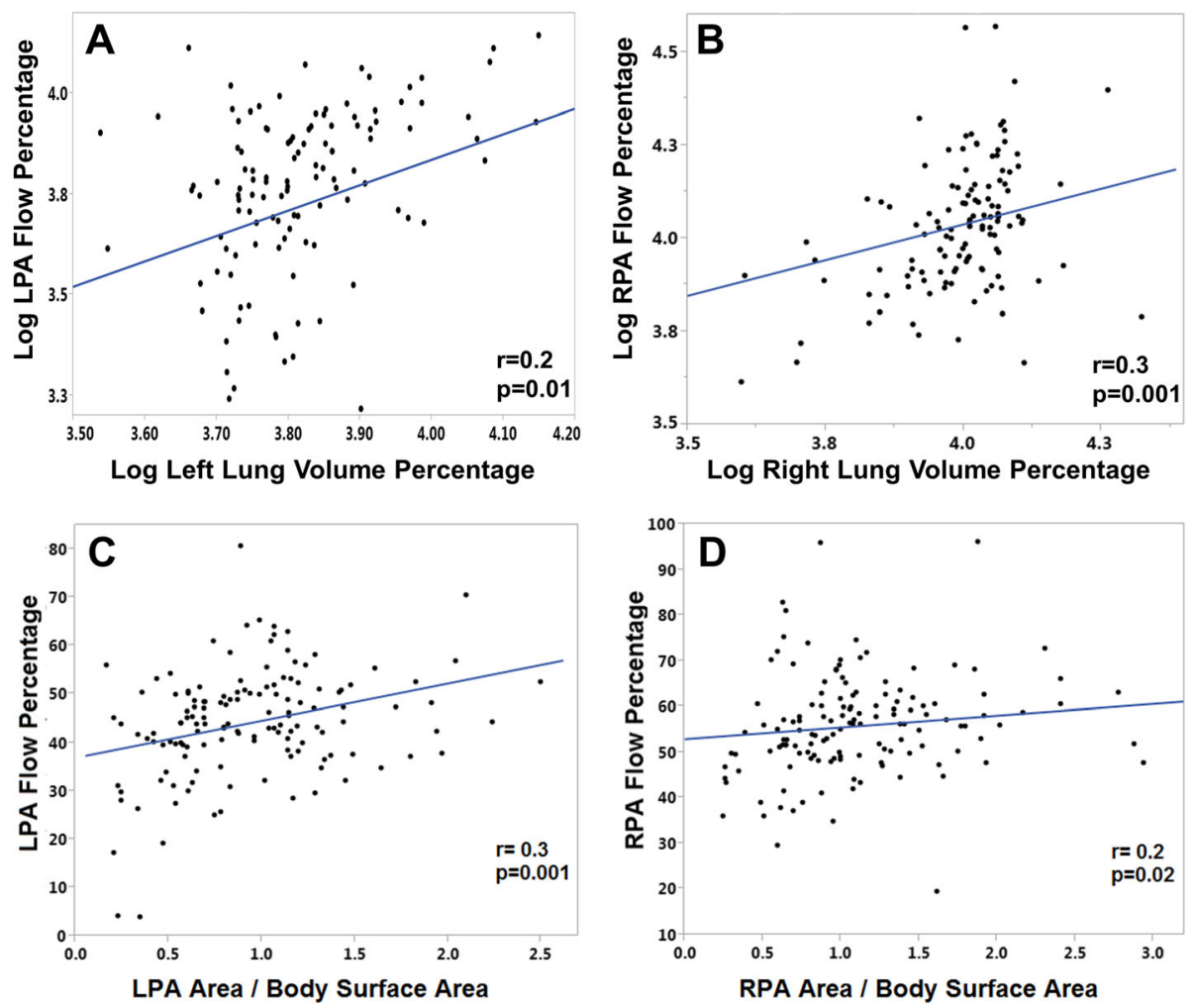

Fig. 3 Association between branch PA flow percentage and lung volume percentage $(\mathbf{a}, \mathbf{b})$ and ipsilateral PA cross sectional area $(\mathbf{c}$, $\mathbf{d}) . N=140$. The estimate $r$ denotes Pearson correlation coefficient. LPA: Left pulmonary artery. RPA: Right pulmonary artery. Log: Logarithmic transformation 


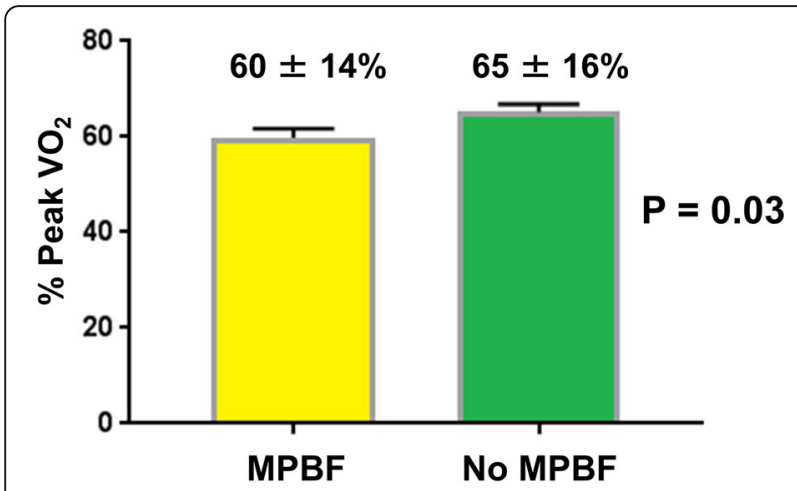

Fig. 4 Patients with maldistribution of pulmonary blood flow (MPBF, $n=53$; yellow) had lower mean \% predicted peak $\mathrm{VO}_{2}$ compared to patients with no MPBF ( $n=94$, green). Error bars denote one standard deviation

cross-sectional area and less than $10 \%$ of the variability can be explained by cross sectional area $\left(r^{2}<0.1\right)$ (Fig. 3). Similarly there was a weak correlation between branch PA flow percentage and lung volume percentage (Fig. 3).

\section{MPBF and exercise capacity}

The mean $\%$ predicted $\mathrm{VO}_{2}$ was $63 \pm 16 \%$. Patients with MPBF had lower \% predicted $\mathrm{VO}_{2}$ compared to patients without MPBF $(60 \pm 14 \%$ versus $65 \pm 16 \% ; p=0.04)$ (Fig. 4). Additional univariate associations of lower \% predicted $\mathrm{VO}_{2}$ are shown in Table 2 and included longer time since Fontan, older age at the Fontan operation, atriopulmonary connection Fontan, heart failure symptoms, presence of a fenestration, and a higher ventricular mass-to-volume ratio. On multivariable analysis, only MPBF, time since Fontan, and ventricular mass-to-volume ratio were associated with a lower \% predicted $\mathrm{VO}_{2}$ (Table 3).

\section{MPBF and clinical outcomes}

During a median follow-up period of 4.2 years [IQR 2.18.4] after the CMR, 14 (10\%) patients died or were listed for heart transplant. Of the 10 patients who died, deaths were attributed to arrhythmias $(n=4)$, heart failure $(n=4)$, renal failure $(n=1)$, and protein losing enteropaty $(n=1)$. The follow-up period was similar among those with and without MPBF (Table 4). MPBF was not associated with death or listing for transplant $(p=0.60)$. MPBF was not associated with other comorbidities including atrial flutter, heart failure, protein-losing enteropathy, major thrombotic events, liver disease, or stroke (Table 4).

\section{Parameters associated with MPBF}

On univariate analysis, a surgical history of a Damus-Kaye-Stansel anastomosis, having a cardiac diagnosis of HLHS, prior Glenn procedure, and history of prior PA intervention were associated with MPBF (Table 1). The CMR parameters and their associations with MPBF are shown in Table 5. On univariate analysis, MPBF was associated with larger ventricular volumes, increased aortopulmonary collateral flow, larger ascending aorta and aortic

Table 2 Univariate Associations with \% Predicted $\mathrm{VO}_{2}$

\begin{tabular}{|c|c|c|c|}
\hline Predictor & R or standardized $\beta$ & Parameter Estimate \pm SE & $P$ value \\
\hline Maldistribution of pulmonary blood flow $(n=147)$ & -0.17 & $-5.4 \pm 2.6^{\mathrm{a}}$ & 0.04 \\
\hline Mass-to-volume ratio $(\mathrm{g} / \mathrm{ml})(n=140)$ & -0.24 & $-19.38 \pm 6.60^{b}$ & 0.004 \\
\hline Age at Fontan (year) $(n=139)$ & -0.20 & $-0.47 \pm 0.19^{b}$ & 0.02 \\
\hline Old type Fontan (RA-PA or RA-RV conduit) $(n=146)$ & -0.27 & $-9.2 \pm 2.8^{\mathrm{a}}$ & 0.001 \\
\hline CHF symptoms $(n=146)$ & -0.21 & $-7.6 \pm 2.9^{\mathrm{a}}$ & 0.01 \\
\hline Atrial arrhythmia $(n=146)$ & -0.29 & $-9.4 \pm 2.6^{\mathrm{a}}$ & 0.001 \\
\hline Fenestration $(n=139)$ & -0.17 & $-1 \pm 0.4^{a}$ & 0.04 \\
\hline Age at CMR (year) $(n=146)$ & -0.36 & $-0.55 \pm 0.12^{b}$ & 0.001 \\
\hline Time since Fontan (year) $(n=139)$ & -0.30 & $-0.67 \pm 0.18^{b}$ & 0.001 \\
\hline Indexed end diastolic volume $\left(\mathrm{ml} / \mathrm{m}^{2}\right)(n=145)$ & 0.10 & $-0.03 \pm 0.04^{b}$ & 0.90 \\
\hline Indexed end systolic volume $\left(\mathrm{ml} / \mathrm{m}^{2}\right)(n=145)$ & -0.10 & $-0.07 \pm 0.05^{b}$ & 0.16 \\
\hline Ejection fraction (\%) $(n=145)$ & 0.10 & $0.23 \pm 0.14^{b}$ & 0.15 \\
\hline Indexed stroke volume $\left(\mathrm{ml} / \mathrm{m}^{2}\right)(n=145)$ & 0.01 & $0.01 \pm 0.10^{b}$ & 0.94 \\
\hline Branch pulmonary artery symmetry index $(n=147)$ & 0.04 & $2.52 \pm 5.52^{\mathrm{b}}$ & 0.64 \\
\hline Systemic left ventricle $(n=144)$ & 0.01 & $-0.5 \pm 3.0^{\mathrm{a}}$ & 0.84 \\
\hline Heterotaxy $(n=147)$ & 0.01 & $-3.3 \pm 4.0^{\mathrm{a}}$ & 0.41 \\
\hline
\end{tabular}

Abbreviations: $P A$ pulmonary artery, $R A$ right atrium, $R V$ right ventricle

${ }^{a}$ Mean difference $\pm S E$ for presence vs. absence of maldistribution of pulmonary blood flow

${ }^{\mathrm{b}} \mathrm{Slope} \pm \mathrm{SE} . \mathrm{SE}=$ standard error 
Table 3 Multivariable Model for $\%$ Predicted $\mathrm{VO}_{2}(n=140)$

\begin{tabular}{llll}
\hline Variable & Standardized $\beta$ coefficient & Parameter Estimate \pm SE & $P$ value \\
\hline Maldistribution of pulmonary blood flow & -0.20 & $-5.4 \pm 2.6^{\text {a }}$ & 0.03 \\
Time since Fontan (year) & -0.32 & $-0.67 \pm 0.18^{\mathrm{b}}$ & 0.002 \\
Ventricular mass-to-volume ratio $(\mathrm{g} / \mathrm{ml})$ & -0.24 & $-19.38 \pm 6.60^{\mathrm{b}}$ & 0.02 \\
\hline
\end{tabular}

${ }^{a}$ Mean difference \pm SE for presence vs. absence of maldistribution of pulmonary blood flow

${ }^{\mathrm{b}} \mathrm{Slope} \pm \mathrm{SE} . \mathrm{SE}=$ standard error

root cross-sectional areas, PA compression by the ascending aorta or aortic root, PASI, and larger lung volume discrepancies. On multivariable logistic regression analysis, only PA compression by the ascending aorta or aortic root was associated with MPBF (OR $=6.5,95 \%$ confidence interval 5.6-7.4, $p<0.001)$. Branch PA compression was seen in 32 patients (21\%), and involved the LPA in 30 patients and the RPA in 2 patients.

\section{Discussion}

This study evaluated the PA blood flow distribution in 147 patients with a Fontan circulation. Patients with MPBF, defined as a difference between LPA and RPA blood flow of $>20 \%$, had lower exercise capacity compared to patients without MPBF. Previous studies have shown that \% predicted $\mathrm{VO}_{2}$ is an independent predictor of mortality in Fontan patients with a hazard ratio of 0.88 for each $1 \%$ increase in $\%$ predicted $\mathrm{VO}_{2}$ [22]. This would imply that our measured difference of $5 \%$ predicted $\mathrm{VO}_{2}$ is likely clinically significant. There were no other associations between MPBF and other clinical outcomes, including death or listing for transplantation. Patients with PA compression by a dilated ascending aorta or aortic root were the most likely to have MPBF.

Previous investigators have used CMR to evaluate PA blood flow distribution in normal subjects and patients with a Fontan circulation [4]. In individuals without congenital heart disease, $55 \%$ of PA blood flow is through the
RPA and $45 \%$ through the LPA. This difference has been attributed to the smaller left lung volume due to the heart being in the left side of the chest [23]. In Fontan patients, Whitehead et al. demonstrated that, on average, RPA flow is $55 \%$ of the total PA flow. Likewise, our study showed similar flow to the RPA (56\% of total PA blood flow) [24]. Both our study and previous studies revealed wide variations in PA blood flow distribution in Fontan patients. Whitehead et al. showed that the prevalence of MPBF is about $45 \%$; however, the study was not designed to look at the associations with clinical outcomes or exercise capacity [4]. In our cohort, MPBF was common, seen in 36\% of patients. The variability of PA blood flow distribution in our study is likely multifactorial and can be only partially explained by lung volume discrepancy as there was only a weak association with lung volumes.

Many variables were associated with MPBF in univariate analysis. On multivariable analysis, only branch PA compression by the ascending aorta or the aortic root had a significant association with MPBF. Previous studies showed that severe aortic root dilation or ascending aortic dilation is seen commonly in patients with Fontan circulation and was associated with aortic regurgitation [25]. Our study suggests that another adverse effect of aortic dilation is PA compression which can lead to MPBF, especially in patients with a left aortic arch leading to LPA compression. PA compression by the aortic root and the ascending aorta was recognized as a problem after the Stage I palliation that can

Table 4 Clinical Outcomes in Patients with and without MPBF

\begin{tabular}{|c|c|c|c|c|}
\hline & $\begin{array}{l}\text { All patients } \\
(n=147)\end{array}$ & $\begin{array}{l}\text { With MPBF } \\
(n=53)\end{array}$ & $\begin{array}{l}\text { Without MPBF } \\
(n=94)\end{array}$ & $\begin{array}{l}P \\
\text { value }\end{array}$ \\
\hline Follow-up time post CMR (year) & $4.2[2.1-8.4]$ & $4.1[1.7-9.1]$ & $4.4[2.4-8.9]$ & 0.59 \\
\hline Death & $10(7 \%)$ & $4(8 \%)$ & $6(6 \%)$ & 0.70 \\
\hline Death / listing for transplantation & $14(10 \%)$ & $6(11 \%)$ & $8(9 \%)$ & 0.60 \\
\hline Liver disease & $50(34 \%)$ & $16(30 \%)$ & $34(36 \%)$ & 0.58 \\
\hline Heart failure & $35(24 \%)$ & $15(29 \%)$ & $20(22 \%)$ & 0.42 \\
\hline Thrombus & $28(19 \%)$ & $12(22 \%)$ & $16(17 \%)$ & 0.50 \\
\hline Seizures & $16(11 \%)$ & $6(11 \%)$ & $10(11 \%)$ & 0.90 \\
\hline Stroke & $26(18 \%)$ & $11(21 \%)$ & $15(17)$ & 0.50 \\
\hline Protein-losing enteropathy & $5(3 \%)$ & $1(2 \%)$ & $4(4 \%)$ & 0.40 \\
\hline Atrial flutter post-Fontan & $32(22 \%)$ & $11(21 \%)$ & $21(22 \%)$ & 0.90 \\
\hline
\end{tabular}

Abbreviations: MPBF maldistribution of pulmonary blood flow

${ }^{*}$ Fisher exact test $p$-value for all variables except follow-up time (Mann-Whitney U Test) 
Table 5 CMR Parameter Associations with MPBF

\begin{tabular}{|c|c|c|c|c|}
\hline & All patients $(n=147)$ & With MPBF $(n=53)$ & Without MPBF $(n=94)$ & $P$ value \\
\hline Ventricular end-diastolic volume (ml/BSA $\left.A^{1.3}\right)$ & $98 \pm 29$ & $104 \pm 35$ & $94 \pm 25$ & 0.05 \\
\hline Ventricular end-systolic volume (ml/BSA $\left.{ }^{1.3}\right)$ & $49 \pm 25$ & $54 \pm 26$ & $46 \pm 19$ & 0.04 \\
\hline Aortopulmonary collateral flow (\%) & $12[3-23]$ & $16[4-27]$ & $10[3-20]$ & 0.02 \\
\hline Ascending aorta area $\left(\mathrm{cm}^{2}\right)$ & $4.9 \pm 2.7$ & $5.8 \pm 3.7$ & $4.4 \pm 1.9$ & 0.001 \\
\hline Total aortic root area $\left(\mathrm{cm}^{2}\right)$ & $6.9 \pm 1.9$ & $5.6 \pm 1.7$ & $5.1 \pm 1.8$ & 0.03 \\
\hline Pulmonary artery symmetry index (\%) & $65 \pm 24$ & $59 \pm 25$ & $68 \pm 23$ & 0.02 \\
\hline Pulmonary artery compression by the ascending aorta or aortic root & $32(22 \%)$ & $21(39 \%)$ & $11(12 \%)$ & 0.001 \\
\hline Lung volume percentage difference (\%) & $13 \pm 9$ & $15 \pm 7$ & $12 \pm 9$ & 0.04 \\
\hline Indexed ventricular stroke volume $\left(\mathrm{ml} / \mathrm{m}^{2}\right)$ & $57 \pm 11$ & $60 \pm 13$ & $56 \pm 12$ & 0.55 \\
\hline Ventricular mass-to-volume ratio (gram/ml) & $0.55 \pm 0.19$ & $0.53 \pm 0.20$ & $0.58 \pm 0.18$ & 0.13 \\
\hline Indexed Ventricular mass $\left(\mathrm{g} / \mathrm{m}^{2}\right)$ & $61.8 \pm 19$ & $62.0 \pm 21$ & $61.7 \pm 18$ & 0.77 \\
\hline
\end{tabular}

Abbreviations: MPBF: maldistribution of pulmonary blood flow; BSA: body surface area

lead to long-term PA hypoplasia in previous studies [2628]. This resulted in multiple modifications of the surgical technique including changing the direction of the Blalock-Taussig shunt leftward into the retroaortic PA to avoid development of LPA stenosis and using more ring-enforced RV-PA conduits in addition to patch augmentation of the LPA [26-28].

Our study as with others found significant exercise impairment in Fontan patients (mean \% predicted $\mathrm{VO}_{2}$ of 63\%) $[22,29]$. Previously reported determinants of exercise capacity include the inability to increase stroke volume at peak exercise, chronotropic impairment, diastolic dysfunction, and power loss in the Fontan circulation [30, 31]. Non-cardiac factors including age, muscle mass and conditioning are also important determinants [30, 31]. In addition to confirming the independent association of time since Fontan and ventricular mass-to-volume ratio with exercise capacity, our study introduces MPBF as another factor that adversely affects exercise capacity in the Fontan population.

We found a weak correlation between ipsilateral PA blood flow and PA size. These data would suggest that reliance solely on PA size (either by echocardiography or angiography) might not correlate well with differential PA blood flow. Direct PA blood flow assessment by CMR should be preferred.

MPBF may result in ventilation perfusion mismatch and less efficient gas exchange within the lungs [32]. MPBF, especially in the case of branch PA stenosis or compression, may also result in elevated Fontan baffle pressures which could lead to an increase in veno-venous collaterals to the pulmonary veins, which can cause systemic desaturation [33]. Fontan patients with severe unilateral branch PA stenosis have been noted to have significantly lower saturations compared to patients without stenosis [33]. Lower oxygen saturation has also been associated with lower exercise capacity in patients with congenital heart disease [4, 34, 35]. Finally, MPBF may also be associated with significant power loss in the Fontan circuit. Previous elegant work using computational flow dynamics showed that power loss correlates to the minimum cross sectional PA area in Fontan patients [36]. MPBF may be a surrogate for the potential power loss in the Fontan circuit [37]. It is also plausible that during exercise, the differences in PA blood flow may be magnified. This may explain why a small measured effect in MPBF at rest has significant impact on functional exercise capacity. Future real time CMR studies during exercise may increase our understanding of the relationships between MPBF, power loss, and exercise capacity.

\section{Limitations}

This is a single-center CMR study which may limit the generalizability of these results to all Fontan patients. In particular, patients with pacemakers and defibrillators could not be evaluated; these devices are used in 13\% of patients with Fontan circulation [37]. Sicker patients and patients with symptoms could be over-represented in this study, as these patients are more likely to be evaluated by CMR [38]. Also, 78 patients were excluded due to the incomplete flow data. Many of these patients had branch PA stents and may have had severe MPBF. Finally, this study included only patients with a maximal CPET, which limited the sample size and may have caused selection bias toward patients with higher functional status.

\section{Conclusion}

In patients after the Fontan operation, MPBF was common, seen in more than one third of patients. Lower exercise capacity was independently associated with MPBF, longer time since Fontan, and increased ventricular mass-to-volume ratio. Patients with PA compression by the aortic root or the ascending aorta were more likely to have MPBF. This study identifies MPBF as an important risk factor and as a potential target for therapeutic interventions in this fragile patient population. 


\section{Abbreviations}

BSA: Body surface area; bSSFP: Balanced steady state free precession; CMR: Cardiovascular magnetic resonance; CPET: Cardiopulmonary exercise test; HLHS: Hypoplastic left heart syndrome; LPA: Left pulmonary artery; MPBF: Maldistribution of pulmonary blood flow; PA: Pulmonary artery; PASI: Pulmonary artery symmetry index; RPA: Right pulmonary artery; $\mathrm{VO}_{2}$ : Oxygen update

\section{Relationship with industry}

No relevant relationships with industry.

\section{Acknowledgements}

Dr. Mark Fogel served as a Guest Editor for this manuscript.

\section{Funding}

This study was supported by the Higgins Family Noninvasive Cardiac Imaging Research Funds.

\section{Availability of data and materials}

The datasets generated and/or analyzed during the current study are not publicly available due to patient privacy concern and institutional policies but are available from the corresponding author on reasonable request.

\section{Authors' contributions}

TA, LS, SJG, TG, AJP, RHR: participated in study design and were major contributors in writing the manuscript. TA, LS, RHR: analyzed and interpreted patient data. TA, MM, NA, RHR: participated in chart review and CMR image interpretation and data gathering. All authors read and approved the final manuscript.

\section{Ethics approval and consent to participate}

The Boston Children's Hospital Committee on Clinical Investigation approved this retrospective study and waived the requirement for informed consent.

\section{Consent for publication}

Not applicable.

\section{Competing interests}

The authors declare that they have no competing interests.

\section{Publisher's Note}

Springer Nature remains neutral with regard to jurisdictional claims in published maps and institutional affiliations.

Received: 5 June 2018 Accepted: 9 November 2018

Published online: 17 December 2018

\section{References}

1. Alsaied T, Bokma JP, Engel ME, Kuijpers JM, Hanke SP, Zuhlke L, Zhang B, Veldtman GR. Factors associated with long-term mortality after Fontan procedures: a systematic review. Heart. 2017;103(2):104-10.

2. d'Udekem Y, lyengar AJ, Galati JC, Forsdick V, Weintraub RG, Wheaton GR, Bullock A, Justo RN, Grigg LE, Sholler GF, et al. Redefining expectations of long-term survival after the Fontan procedure: twenty-five years of followup from the entire population of Australia and New Zealand. Circulation. 2014;130(11 Suppl 1):S32-8.

3. Alsaied T, Bokma JP, Engel ME, Kuijpers JM, Hanke SP, Zuhlke L, Zhang B, Veldtman GR. Predicting long-term mortality after Fontan procedures: a risk score based on 6707 patients from 28 studies. Congenit Heart Dis. 2017; 12(4):393-8

4. Whitehead KK, Sundareswaran KS, Parks WJ, Harris MA, Yoganathan AP, Fogel MA. Blood flow distribution in a large series of patients having the Fontan operation: a cardiac magnetic resonance velocity mapping study. J Thorac Cardiovasc Surg. 2009;138(1):96-102.

5. Rathod RH, Prakash A, Kim YY, Germanakis IE, Powell AJ, Gauvreau K, Geva T. Cardiac magnetic resonance parameters predict transplantation-free survival in patients with fontan circulation. Circ Cardiovasc Imaging. 2014;7(3):502-9.

6. Gewillig M, Brown SC. The Fontan circulation after 45 years: update in physiology. Heart. 2016;102(14):1081-6.

7. Bichell DP, Lamberti JJ, Pelletier GJ, Hoecker C, Cocalis MW, Ing FF, Jensen RA. Late left pulmonary artery stenosis after the Norwood procedure is prevented by a modification in shunt construction. Ann Thorac Surg. 2005; 79(5):1656-60 discussion 1660-1651.

8. Konstantinov IE, Naimo PS, d'Udekem Y. Prevention of right pulmonary artery stenosis in Fontan circulation: the Melbourne modification of TFontan operation. Heart Lung Circ. 2016;25(4):405-6.

9. Deal BJ, Jacobs ML. Management of the failing Fontan circulation. Heart. 2012;98(14):1098-104

10. Kotani Y, Zhu J, Grosse-Wortmann L, Honjo O, Coles JG, Van Arsdell GS, Caldarone CA. Anatomical risk factors, surgical treatment, and clinical outcomes of left-sided pulmonary vein obstruction in single-ventricle patients. J Thorac Cardiovasc Surg. 2015;149(5):1332-8.

11. Haggerty CM, Restrepo M, Tang E, de Zelicourt DA, Sundareswaran KS, Mirabella L, Bethel J, Whitehead KK, Fogel MA, Yoganathan AP. Fontan hemodynamics from 100 patient-specific cardiac magnetic resonance studies: a computational fluid dynamics analysis. J Thorac Cardiovasc Surg. 2014;148(4):1481-9.

12. Paridon SM, Mitchell PD, Colan SD, Williams RV, Blaufox A, Li JS, Margossian R, Mital S, Russell J, Rhodes J. A cross-sectional study of exercise performance during the first 2 decades of life after the Fontan operation. J Am Coll Cardiol. 2008;52(2):99-107.

13. Garg R, Powell AJ, Sena L, Marshall AC, Geva T. Effects of metallic implants on magnetic resonance imaging evaluation of Fontan palliation. Am J Cardiol. 2005;95(5):688-91.

14. Prakash A, Rathod RH, Powell AJ, McElhinney DB, Banka P, Geva T. Relation of systemic-to-pulmonary artery collateral flow in single ventricle physiology to palliative stage and clinical status. Am J Cardiol. 2012;109(7):1038-45.

15. Rathod RH, Prakash A, Powell AJ, Geva T. Myocardial fibrosis identified by cardiac magnetic resonance late gadolinium enhancement is associated with adverse ventricular mechanics and ventricular tachycardia late after Fontan operation. J Am Coll Cardiol. 2010;55(16):1721-8.

16. Powell AJ, Geva T. Blood flow measurement by magnetic resonance imaging in congenital heart disease. Pediatr Cardiol. 2000;21(1):47-58.

17. Glatz AC, Petit CJ, Goldstein BH, Kelleman MS, McCracken CE, McDonnell A, Buckey T, Mascio CE, Shashidharan S, Ligon RA, et al. A comparison between patent ductus arteriosus stent and modified Blalock-Taussig shunt as palliation for infants with ductal-dependent pulmonary blood flow: insights from the congenital catheterization research collaborative. Circulation. 2018;137(6):589-601.

18. Burman ED, Keegan J, Kilner PJ. Pulmonary artery diameters, cross sectional areas and area changes measured by cine cardiovascular magnetic resonance in healthy volunteers. J Cardiovasc Magn Reson. 2016;18:12.

19. Beroukhim RS, Graham DA, Margossian R, Brown DW, Geva T, Colan SD. An echocardiographic model predicting severity of aortic regurgitation in congenital heart disease. Circ Cardiovasc Imaging. 2010;3(5):542-9.

20. Balady GJ, Arena R, Sietsema K, Myers J, Coke L, Fletcher GF, Forman D, Franklin B, Guazzi M, Gulati M, et al. Clinician's guide to cardiopulmonary exercise testing in adults: a scientific statement from the American Heart Association. Circulation. 2010;122(2):191-225.

21. Arena R, Myers J, Abella J, Pinkstaff S, Brubaker P, Moore B, Kitzman D, Peberdy MA, Bensimhon D, Chase $P$, et al. Determining the preferred percent-predicted equation for peak oxygen consumption in patients with heart failure. Circ Heart Fail. 2009;2(2):113-20.

22. Ohuchi H, Negishi J, Noritake K, Hayama Y, Sakaguchi H, Miyazaki A, Kagisaki K, Yamada O. Prognostic value of exercise variables in 335 patients after the Fontan operation: a 23-year single-center experience of cardiopulmonary exercise testing. Congenit Heart Dis. 2015;10(2):105-16.

23. Cheng CP, Herfkens RJ, Taylor CA, Feinstein JA. Proximal pulmonary artery blood flow characteristics in healthy subjects measured in an upright posture using MRl: the effects of exercise and age. J Magn Reson Imaging 2005;21(6):752-8.

24. Henk CB, Schlechta B, Grampp S, Gomischek G, Klepetko W, Mostbeck GH. Pulmonary and aortic blood flow measurements in normal subjects and patients after single lung transplantation at $0.5 \mathrm{~T}$ using velocity encoded cine MRI. Chest. 1998;114(3):771-9.

25. Kim YY, Rathod RH, Gauvreau K, Keenan EM, Del Nido P, Geva T. Factors associated with severe aortic dilation in patients with Fontan palliation. Heart. 2017;103(4):280-6.

26. Caspi J, Pettitt TW, Mulder T, Stopa A. Development of the pulmonary arteries after the Norwood procedure: comparison between Blalock-Taussig shunt and right ventricular-pulmonary artery conduit. Ann Thorac Surg. 2008;86(4):1299-304. 
27. Bentham JR, Baird CW, Porras DP, Rathod RH, Marshall AC. A reinforced right-ventricle-to-pulmonary-artery conduit for the stage-1 Norwood procedure improves pulmonary artery growth. J Thorac Cardiovasc Surg. 2015;149(6):1502-8 e1501.

28. Nassar MS, Bertaud S, Goreczny S, Greil G, Austin CB, Salih C, Anderson D, Hussain T. Technical and anatomical factors affecting the size of the branch pulmonary arteries following first-stage Norwood palliation for hypoplastic left heart syndrome. Interact Cardiovasc Thorac Surg. 2015;20(5):631-5.

29. Ohuchi H. Cardiopulmonary response to exercise in patients with the Fontan circulation. Cardiol Young. 2005;15(Suppl 3):39-44.

30. Goldberg DJ, Avitabile CM, McBride MG, Paridon SM. Exercise capacity in the Fontan circulation. Cardiol Young. 2013;23(6):824-30.

31. Paridon SM, Mitchell PD, Colan SD, Williams RV, Blaufox A, Li JS, Margossian R, Mital S, Russell J, Rhodes J, et al. A cross-sectional study of exercise performance during the first 2 decades of life after the Fontan operation. J Am Coll Cardiol. 2008;52(2):99-107.

32. Sutton NJ, Peng L, Lock JE, Lang P, Marx GR, Curran TJ, O'Neill JA, Picard ST, Rhodes $\mathrm{J}$. Effect of pulmonary artery angioplasty on exercise function after repair of tetralogy of Fallot. Am Heart J. 2008;155(1):182-6.

33. Zachary CH, Jacobs ML, Apostolopoulou S, Fogel MA. One-lung Fontan operation: hemodynamics and surgical outcome. Ann Thorac Surg. 1998; 65(1):171-5.

34. Glaser S, Opitz CF, Bauer U, Wensel R, Ewert R, Lange PE, Kleber FX. Assessment of symptoms and exercise capacity in cyanotic patients with congenital heart disease. Chest. 2004;125(2):368-76.

35. Whitehead KK, Pekkan K, Kitajima HD, Paridon SM, Yoganathan AP, Fogel MA. Nonlinear power loss during exercise in single-ventricle patients after the Fontan: insights from computational fluid dynamics. Circulation. 2007; 116(11 Suppl):1165-71.

36. Dasi LP, Krishnankuttyrema R, Kitajima HD, Pekkan K, Sundareswaran KS, Fogel M, Sharma S, Whitehead K, Kanter K, Yoganathan AP. Fontan hemodynamics: importance of pulmonary artery diameter. J Thorac Cardiovasc Surg. 2009;137(3):560-4

37. Anderson PA, Sleeper LA, Mahony L, Colan SD, Atz AM, Breitbart RE, Gersony WM, Gallagher D, Geva T, Margossian R, et al. Contemporary outcomes after the Fontan procedure: a Pediatric Heart Network multicenter study. J Am Coll Cardiol. 2008;52(2):85-98.

38. Fernandes $S M$, Alexander ME, Graham DA, Khairy P, Clair M, Rodriguez E, Pearson DD, Landzberg MJ, Rhodes J. Exercise testing identifies patients at increased risk for morbidity and mortality following Fontan surgery. Congenit Heart Dis. 2011;6(4):294-303.

Ready to submit your research? Choose BMC and benefit from:

- fast, convenient online submission

- thorough peer review by experienced researchers in your field

- rapid publication on acceptance

- support for research data, including large and complex data types

- gold Open Access which fosters wider collaboration and increased citations

- maximum visibility for your research: over $100 \mathrm{M}$ website views per year

At BMC, research is always in progress.

Learn more biomedcentral.com/submissions 